\title{
LA HUMANIZACIÓN DEL ESPACIO PÚBLICO: EL CORAZÓN URBANO COMO LUGAR DE EXPRESIÓN DE LA SOCIEDAD MODERNA
}

\author{
Emilio Cachorro Fernández \\ Universidad de Granada \\ ecachorro@ugr.es \\ ORCID iD: https://orcid.org/0000-0002-7314-9928
}

Recibido: 08/01/2019; Aceptado: 30/09/2019.

\begin{abstract}
Cómo citar este artículo/Citation: Cachorro Fernández, E. (2019). La humanización del espacio público: el corazón urbano como lugar de expresión de la sociedad moderna. Estudios Geográficos, 80 (287), e024. https://doi.org/10.3989/estgeogr.201941.021

RESUMEN: Los centros urbanos siempre han desempeñado un decisivo papel impulsor de la vida comunitaria, en cuanto que lugares físicos reconocibles donde se intensifica socialmente la confluencia, aunque con fluctuaciones en modo e intensidad según la época. El desarrollo industrial provocó la desarticulación de las ciudades debido a su crecimiento desenfrenado, relegando a la mayoría de la población al extrarradio, con el riesgo de perder sus valores tradicionales como colectividad por culpa de una excesiva disgregación. Un gradual proceso que alertó de la necesidad de nuevos modelos capaces de recuperar la cohesión social, más aún tras la coyuntura de reconstrucción suscitada en la segunda posguerra mundial. Por esta razón, se aborda el estudio del "corazón de la ciudad" durante el último siglo, con el fin de profundizar en la diferente consideración de que ha sido objeto en cada período, a partir de una serie de precedentes que nos sitúan en los albores de la modernidad, cuando fueron surgiendo diferentes posicionamientos ideológicos que se han ido ampliando y revisando con el paso de las décadas y que, seleccionados por su relevancia y confrontados para un mejor análisis, claman en favor de restablecer la integración tomando como base los espacios de encuentro y relación.
\end{abstract}

PALABRAS CLAVE: planificación urbana; centro urbano; corazón de la ciudad; espacio público; siglo XX.

\section{THE HUMANIZATION OF PUBLIC SPACE: THE URBAN HEART AS PLACE OF EXPRESSION OF MODERN SOCIETY}

ABSTRACT: Urban centers have always played a crucial role in driving force behind the community life, as recognizable physical places where social confluence is intensified, although with fluctuations in mode and intensity depending on the age. Industrial development led to the dismantling of the cities due to their unbridled growth, relegating most of the population to the periphery, with the risk of losing their traditional values as society because of excessive disintegration. A gradual process that warned of the need for new models able to remake the social cohesion, even more after the situation of post-World War II reconstruction. For this reason, the "heart of the city" during the last century is selected as subject of research, in order to deepen in the different consideration that it has had in each period, from a series of precedents that put us at the dawn of the modernity, when different ideological positions were emerging to be increased and reviewed over the decades and which, selected for their relevance and compared for better analysis, cry out in favor of restoring the integration based on meeting and relationship places.

KEY WORDS: town planning; urban center; heart of the city; public space; twentieth century. 


\section{INTRODUCCIÓN}

La polis nace, conceptual y morfológicamente, de la delimitación regular de un recinto vacío, tenido como lugar de ayuntamiento civil, donde discutir sobre lo público (Ortega, 1930, p. 154). Históricamente ha sido así. La conciencia democrática de los antiguos griegos se exteriorizó en el ágora -término derivado de agheirein que significa 'encuentro' y, a su vez, origen de agorazein cuya traducción es 'ir al mercado, comprar, conversar' (Burckhardt, 1898, p. 76)- como espacio expresivo de la estructura social y física de la urbe, inicialmente asociado con actividades de entretenimiento como fiestas, juegos, deporte y teatro, pero cuyo principal uso era asambleario, pese a que también acabó por aglutinar el comercio; según Pausanias (s. Il d. C., $X, 4.1$ ), no debía considerarse que un asentamiento tuviera rango de ciudad si no era poseedor de su particular kerameikos. Una configuración con centralidad remarcada en la civitas, donde la intersección de ejes posicionaba un foro igualmente habilitado para congregación y espectáculos, asumiendo mayor carga institucional y monumental, mediante una implantación desordenada que mantuvo la prioridad del viandante, aunque incorporaba cierta discriminación de género como también ocurriría en el maidan islámico.

Tras un período de crisis, la villa medieval recobró el pulso a través del ajetreo mercantil que animaría las calles de burgos y arrabales, en contraste con los decadentes núcleos administrativos y la mermada peatonalización de otras zonas, con un centro cívico autónomo del religioso para, más tarde, volver a imponerse una sola piazza por el dominio aristócrata, pero sin desvirtuar el carácter colectivo que los legitimaba; como declaró Petrus Berchorius en aquella época, desde que las plazas son áreas de pueblos y ciudades dispuestas con el propósito de proporcionar el sitio u organización para confluir, hay que reconocer que es posible descubrir la condición del hombre en este mundo (Kostof, 1992, p. 123). Se había recuperado una tendencia que, desde entonces, se iría fortaleciendo; así, entre otros, Palladio (1570, III, XVI) nos recordaba la necesidad de tener plazas en las que "se reúnan las gentes a pasear, entretenerse y hacer tratos", lo que hizo proliferar grandes salones guiados por los modelos de plaza mayor y place royale-exportados a Iberoamérica-, con una imagen más controlada, de valor simbólico, donde la arquitectura quedaba integrada en un conjunto armónico, bajo la dimensión renacentista y barroca de la ciudad como 'lugar de representación' profano y sacro; una città gioiosa donde urbanismo y escenografía convergieron para exal- tación fastuosa de los distintos poderes, acogiendo la celebración ritual de fiestas, torneos, carnavales y procesiones, además de cortejos y otras ceremonias.

Llegados a este punto, con tan paradigmáticos antecedentes, comenzarían a sucederse muy diversos posicionamientos y reinterpretaciones sobre la idea de centro urbano, así como de su rol específico, a partir del revolucionario surgimiento de la ciudad moderna. Es por ello que, a través del presente texto, se propone retomar dicha particular cuestión, estimada de la máxima trascendencia en los campos tanto de la geografía urbana como del urbanismo, mediante una mirada reflexiva que dirige su foco hacia el siglo $\mathrm{XX}$, recurriendo a un ejercicio de síntesis basado en la recopilación de las más determinantes fuentes bibliográficas sobre la materia, que se someten a una nueva lectura, esta vez de forma conjunta, lo que permite realizar un análisis cruzado o transversal, perfectamente complementario respecto de otros conocidos estudios abordados de forma aislada.

\section{PRELUdios tRANSFORMAdores del MOdelo de Núcleo}

Con el advenimiento de la industrialización, los centros de la denominada ciudad posliberal mantuvieron su hegemonía política y económica, asumiendo su histórica función de escenario cívico de convivencia, complemento necesario de los espacios de trabajo, compatible con todos los planes y reformas decimonónicos, mediante los que la actividad social, sin embargo, decayó en las tradicionales plazas, cuya anterior dimensión representativa y ceremoniosa fue sustituida, según Camilo Sitte (1889, pp. 159-160), por objetivos salubres o estéticos, como la mejora del soleamiento o una menor monotonía edilicia y el realce de ciertas construcciones. En su lugar, el protagonismo sería acaparado por esplendorosos bulevares (Jacobs, 1993) que, a modo de auténticas plateas urbanas, fomentaban la concurrencia y el esparcimiento, con promenades que hacían que cada persona pudiera sentirse «espectadora y espectáculo al mismo tiempo, móvil y errabunda» (Sica, 1977, p. 1053), atrayendo al dinámico flâneur baudelairiano, sin perjuicio de los esporádicos puntos de encuentro que constituían las ferias y exposiciones complacientes del progreso de algunas capitales.

Paralelamente, en Europa también se experimentaban nuevas formas de implantación y crecimiento, de mayoritaria vocación higienista, entre los que despuntó la Ciudad Jardín de Ebenezer Howard, donde se independizaban determinados servicios públicos de las prácticas cotidianas, mediante un esquema concéntrico y radial de avenidas que finalmente con- 
vergían en una agrupación de diversos equipamientos, localizado en la corona circular interna, que se rodeaba con extensas zonas verdes. Y, en Estados Unidos, incorporando una cualidad similar, emergió el movimiento City Beautiful liderado por Daniel Burnham -con influencia de la White City-, que fomentaba los conjuntos monumentales como alternativa aún vigente a las intervenciones haussmanianas de tendencia ingenieril y muy poco preservacionista; de esta manera, en una ciudad tras otra, se comenzaron a levantar importantes centros cívicos o culturales, con un lenguaje Beaux-Arts que los hace ver como una especie de conjuntos históricos importados, fruto de actuaciones unitarias que estructuraban las edificaciones gubernamentales a lo largo de grandes ejes con tratamiento de paseos.

Efecto de lo anterior sería la propagación del Civic Art, que inicialmente se tuvo por "arte en la ciudad" para luego convertirse en "arte de construir la ciudad", mediante una aplicación libre de la estética academicista, pero manteniendo sus criterios de jerarquía, centralidad, etc. Según Raymond Unwin (1909, pp. 131-172), el embellecimiento urbano no consiste en la colocación indiscriminada de elementos como fuentes o esculturas sino en algo más profundo, manifestación del soporte físico de la actividad social, aduciendo que: "Aristóteles definió la ciudad como el lugar donde los hombres llevan una vida en común con un fin noble» (p. 16), lo que debía ser expresado de modo claro e inmediato para mayor estímulo de sus habitantes; en su opinión, dicho aspecto se favorece por medio de planes que enfaticen unas áreas sobre otras, configurando múltiples motivos de interés: uno principal, ocupado normalmente por edificios institucionales, y otros muchos secundarios, organizadores de distritos, barrios y áreas menores, no solo para el emplazamiento de equipamientos públicos sino también como focos de reunión. En este mismo sentido, Werner Hegemann destacó el concepto de plaza en su «consideración de espacio primigenio de lo urbano, expresión física de la sociabilidad, y quintaesencia de los aspectos curativos, maternales, acogedores y humanizadores que se deben encontrar en la vida colectiva» (SoláMorales, 1992, s.p.), al que se supeditarán los edificios; así, las exposiciones universales (ver FIG. 1), los campus universitarios, los centros cívicos, etc. no son otra cosa que variaciones del tema del núcleo metropolitano, cuya novedad consiste, especialmente, en la adaptación a las nuevas escalas y exigencias técnicas, pero reproduciendo las estructuras espaciales de la tradición clásica.
En cualquier caso, los ámbitos promovidos con base en la City Beautiful quedarían completamente aislados dentro del tejido urbano, hasta el punto de no servir para regenerarlo sino todo lo contrario, acentuando las grandes diferencias que reinaban entre sectores, lo que hizo que fueran percibidos por los vecinos como algo ajeno y distante. Lo que sí perduraría muchas décadas más iba a ser su idea germinal: la supuesta bondad que representaba un potente centro purificado de cualquier uso doméstico. De este modo, se abonó el camino para la mayor expresión estadounidense de polaridad metropolitana, plasmada en las llamadas "ciudades del laissez faire" (Ciucci, Dal Co, Manieri-Elia y Tafuri, 1975, pp. 3-13), que tomaron forma bajo el capitalismo, cuya estructura es comparable a la de las urbes burguesas europeas en cuanto a la concentración productiva en su núcleo, convertido en un importante centro de negocios sobre el que gravitaban las restantes áreas, con monopolio tipológico de edificios en altura para destinos terciarios, que obvian las relaciones de proporcionalidad con un parcelario neutro resultante de un trazado en retícula -que lo particulariza respecto de otros territorios históricamente consolidados.

\section{EL CORAZÓN DE LA CIUDAD MODERNA}

\section{Crisis del centro urbano}

Tras la entrada del pasado siglo, se comenzó a resolver el estancamiento que sufría la arquitectura durante las últimas décadas. Los partidarios del movimiento moderno empezaron a proyectar edificios desde un posicionamiento funcionalista, preocupados por adaptar las formas a las necesidades del usuario, de una manera cada vez más comprometida y generalizada. Sin embargo, a pesar de ello, el conjunto de la ciudad proseguía en una situación anquilosada, con centros urbanos estériles cuando no desintegrados, viendo proliferar suburbios anárquicos y anodinos, lo que constituía una peligrosa inestabilidad para nuestra forma de habitar comunitaria e identidad colectiva. Ello urgía igualmente a reconducir toda una serie de caducos planteamientos, mediante innovadoras propuestas que pudieran impulsar una deseada evolución, tanto a la hora de intervenir en áreas preexistentes como en nuevas expansiones. Debido a tal circunstancia, esta materia comenzó a tenerse en cuenta para su análisis y debate en cada Congrès International d'Architecture Moderne, donde se abordaría el urbanismo como campo de trabajo, de manera inseparable con la edificación, a partir de 1930. 
FIGURA 1

WORLD'S COLUMBIAN EXPOSITION, CHICAGO (1893)

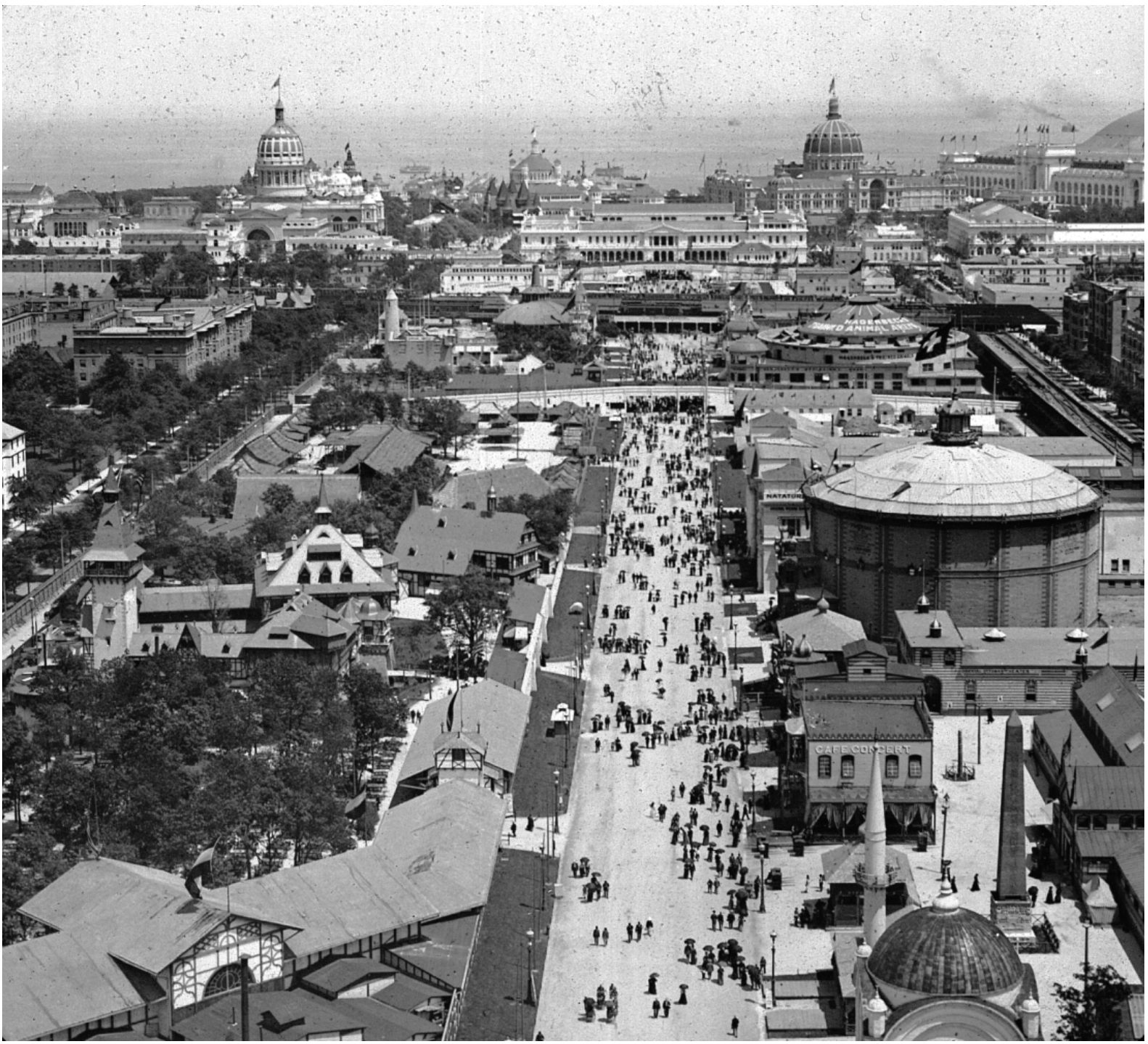

Fuente: Brooklyn Museum Archives (Goodyear Archival Collection). Vista aérea del acceso a la feria a través de Midway Plaisance, tomada desde la Ferris Wheel.

La problemática era tan acusada que, solo tres años después, desencadenó la celebración del legendario cuarto CIAM, dedicado a La cite fonctionelle. En él iba a destacar el discurso pronunciado por Le Corbusier, quien se refirió a los desarrollos extensivos afirmando que, pese a complacer al individuo, ocasionan la pérdida de organización colectiva; por dicha razón, había que decantarse por modelos concentrados, compuestos de grandes rascacielos erigidos gracias a las nuevas tecnologías, que permiten obtener mucha más superficie para espacios libres. De hecho, el punto 2 de la Carta de Atenas, recalcado por el 75, proclama que el ser humano se siente inseguro de manera aislada mientras que encuentra protección al agruparse, pudiendo así satisfacer su profunda necesidad de vida social (Le Corbusier, 1943, pp. 23-24 y 117-118); aquel, convertido en elemento de una comunidad que le ampara, colabora en las empresas que aseguran su vida física y desarrollan su vida espiritual. Como resultado, se proponía una organización urbana basada en la zonificación, desde un racionalismo exacerbado, separando las conocidas cuatro funciones básicas, entre las que debía existir autonomía: habitar, trabajar, circular y recrearse, pero sin hacer mención expresa a un área específica para la interacción ciudadana. 
El estudio de nuevas zonas residenciales donde viviendas, servicios comunes y lugares de ocio estuvieran integrados en un solo proyecto, constituiría el contenido del quinto CIAM, bajo el lema Logis et loisirs, que tuvo lugar en París en 1937, aunque tampoco llegó a reportar conclusiones importantes en relación con los centros urbanos, asumiendo la estructura fragmentada previamente establecida. Lo más reseñable sería la ponencia presentada por Hubert de Cronin Hastings -Presidente de Architectural Press y editor de The Architectural Review-, junto a Aileen y WiIliam Tatton Brown (1937), con el título 'The Theory of Contacts' and its application to the future of London, que hizo hincapié en que los nuevos planes no debían descuidar el imprescindible contacto a nivel social, de manera acorde con las costumbres tradicionales de los pueblos. Un aspecto que, poco a poco, iba a ir calando en la práctica arquitectónica. De hecho, tras el paréntesis de la II Guerra Mundial, el propio Le Corbusier fue invitado a impartir unas conferencias en Nueva York, de forma simultánea a la exposición de su plan para la reconstrucción de Saint-Dié (1945) (ver FIG. 2) en el Rockefeller Center y, meses después, en el Museum of Modern Art, donde se incorporó el proyecto para Ci- dade dos Motores (1943-1947) de José Luis Sert y Paul Lester Wiener, delatando una versión actualizada del urbanismo moderno, en el que se añadía una quinta función: el centro cívico o corazón de la ciudad.

Tal circunstancia ya había sido anticipada por el arquitecto español, junto a Sigfried Giedion y Fernand Léger, en sus célebres Nine points on monumentality (Giedion, 1957, pp. 50-53), formulados en 1943. Un manifiesto, tan breve como clarividente, donde alertaban de la poca atención prestada a la vida comunal urbana hasta ese momento, la cual debía reorganizarse después de las transformaciones de posguerra en las estructuras económicas nacionales; era preciso abandonar los seudoidilios del siglo anterior, admitiendo los medios modernos de creación, únicos con capacidad suficiente para generar monumentos y edificios públicos que reflejaran el espíritu de la época, cuyo emplazamiento debía ser tomado en consideración durante la tarea planificadora, lo que requería reordenar a fondo los centros de las ciudades, para eliminar su caótico estado mediante la habilitación de lugares abiertos, a los que fuera posible vincular los nuevos espacios cívicos y culturales (Giedion, 1997, pp. 159-177).

FIGURA 2

LE CORBUSIER: PROYECTO DE CENTRO CÍVICO, SAINT-DIÉ (1945)

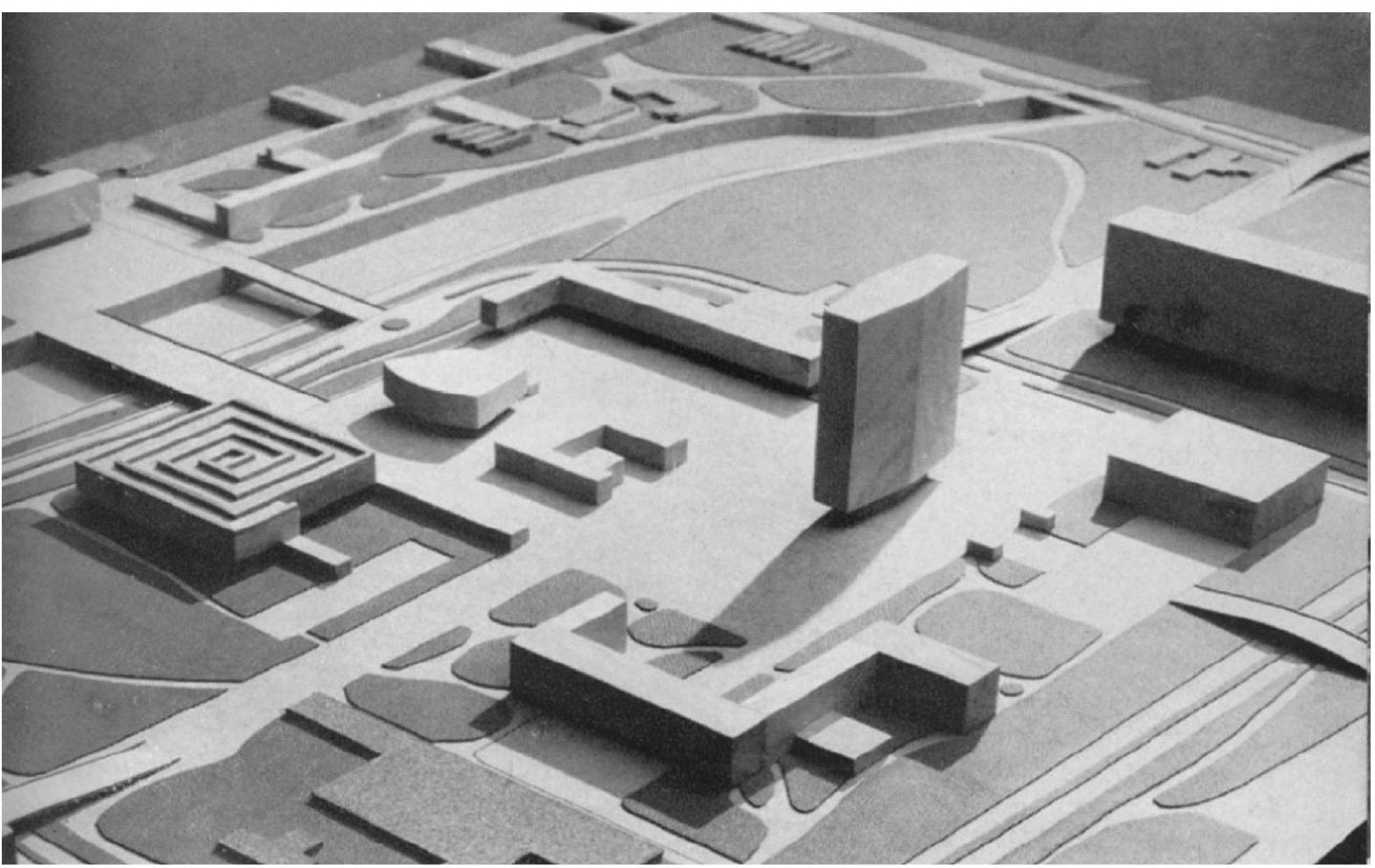

Fuente: Fondation Le Corbusier. Su diseño urbano se compone de edificaciones para centro administrativo, turismo y artesanía, restaurantes, casa comunitaria, museo, hostelería, grandes almacenes y piscina, más un área de "fábricas verdes" en la orilla contraria del río Meurthe. 


\section{El octavo CIAM}

El séptimo congreso, celebrado en Bérgamo en 1949, con Sert actuando como Presidente, propiciaría que este pusiera el acento en la anterior idea, aunque finalmente no fuera aceptada por el pleno de los asistentes, posponiéndose para el simposio siguiente de manera monográfica. Así, con intención de aportar soluciones para reimplantar el equilibrio entre los ámbitos individual y colectivo a nivel urbano, se eligio The heart of the city como objeto de estudio del octavo CIAM, convocado en Hoddesdon en 1951, que tuvo al grupo inglés MARS (Modern Architectural Research Society) como anfitrión, y a una de sus componentes, Jacqueline Tywhitt, como organizadora, con participación de los ya mencionados Le Corbusier, Sert y Giedion junto a Walter Gropius, Jaap Bakema, Ernesto N. Rogers, Richard Neutra, Kenzo Tange, Kunio Maekawa y James Johnson Sweeney, entre otros. La denominación del tema fue propuesta por los británicos, para no limitarse al concepto de civic center, bastante extendido en aquel momento, pero que hace referencia a un área predominantemente administrativa (Giedion, 1997, pp. 181-182). En su lugar, se prefería emplear la palabra core -derivada del vocablo latino cor que significa 'corazón'-, con intención de aludir a la parte central o interna de algo pero con un carácter mucho más abierto; llevado al caso de la ciudad, equivaliendo al núcleo sustancial de ésta, donde nos sentimos identificados como sociedad. Un concepto perfectamente aplicable a cada una de las cinco escalas urbanas que se predeterminaron al efecto: el poblado o la agrupación primaria de casas; la aldea con mercado o el barrio residencial; la localidad rural importante o el distrito; la ciudad; y la metrópoli.

Sert definió el panorama general, haciéndose eco de la indeseable situación urbanística de mediados de siglo debido a las nuevas circunstancias y formas de vida (Rogers, Sert y Tyrwhitt, 1952, p. 6). Por un lado, los revolucionarios medios de comunicación -o telecomunicación, en su condición de sistemas de emisión a larga distancia, como son la radio y la televisión, que venían a sumarse al teléfono- instalados en cada vivienda, auspiciaban la dispersión de asentamientos y gentes; éstos, junto con el cine, la prensa, etc., colmaban la necesidad de intercambio de ideas. De otra parte, los avanzados sistemas de transporte permitían ensanchar ciudades, generando numerosos barrios suburbanos, pero a costa de aumentar distancias, si no en tiempo, sí de modo físico y mental, lo que se agravaba con la conges- tión del tráfico. Todo ello, aunque supuso ventajas y comodidades desconocidas hasta entonces, simultáneamente levantaba importantes barreras artificiales entre la población, causando un notorio menoscabo de las relaciones personales de sus habitantes, echándose en falta espacios, también aptos para turistas, donde realizar las más diversas actividades, disfrutando de diversiones, espectáculos, información cultural..

Se hacía necesario priorizar al usuario frente a la máquina, considerándola siempre un artificio a su servicio, además de retornar urgentemente a la "medida humana" -como reclamaban Le Corbusier y Gropius, empleando esa locución como titular de sus respectivos escritos- (Rogers et al., 1952, pp. 45-48 y 53-55), mediante una adecuada proporción y relación entre masas edificadas y vacíos, en la búsqueda de un perfecto orden; en definitiva, restablecer algunos valores que ya animaban las poblaciones de la antigüedad. Según Giedion (1941, pp. 102-103), el hecho de no disponer de un determinado modo de vida moderna al que dar expresión, no puede ni debe ser excusa para la falta de imaginación mostrada al idear los centros urbanos. Así, Sert escribe que una correcta planificación debe conformar un esquema orgánico que, tras zonificar la ciudad por usos, dotando a cada cual de su propio núcleo, origine una red o constelación en donde sobresalga uno principal que constituya el corazón de la ciudad; su imagen debe ser un conjunto en armonía, donde se imponga la separación entre peatones y automóviles, la presencia de elementos naturales (árboles, agua...) y la protección frente a temperaturas extremas. Además, en dicho entorno, siguiendo la pauta de su maestro, proponía aspirar a "la síntesis de las artes" para su revitalización, como evolución de las tesis racionalistas sostenidas en los años veinte y treinta, a través de edificios no exclusivamente funcionales sino, a la vez, acompañados de un lenguaje de gran libertad plástica, con un vocabulario más completo, en estrecha colaboración con pintores y escultores como había ocurrido en etapas anteriores (Rogers et al., 1952, pp. 11 y 13-16); la arquitectura llevaba demasiado tiempo divorciada de sus disciplinas hermanas. Pero no se trataba de recuperar estilos pasados, que debían sustituirse por recursos actuales; de esta suerte, por ejemplo, escenografías efímeras -logradas con iluminación y elementos móviles- podían reavivar los centros gracias a su continua transformación ${ }^{1}$ (ver FIG. 3). 
FIGURA 3

TIMES SQUARE, NUEVA YORK

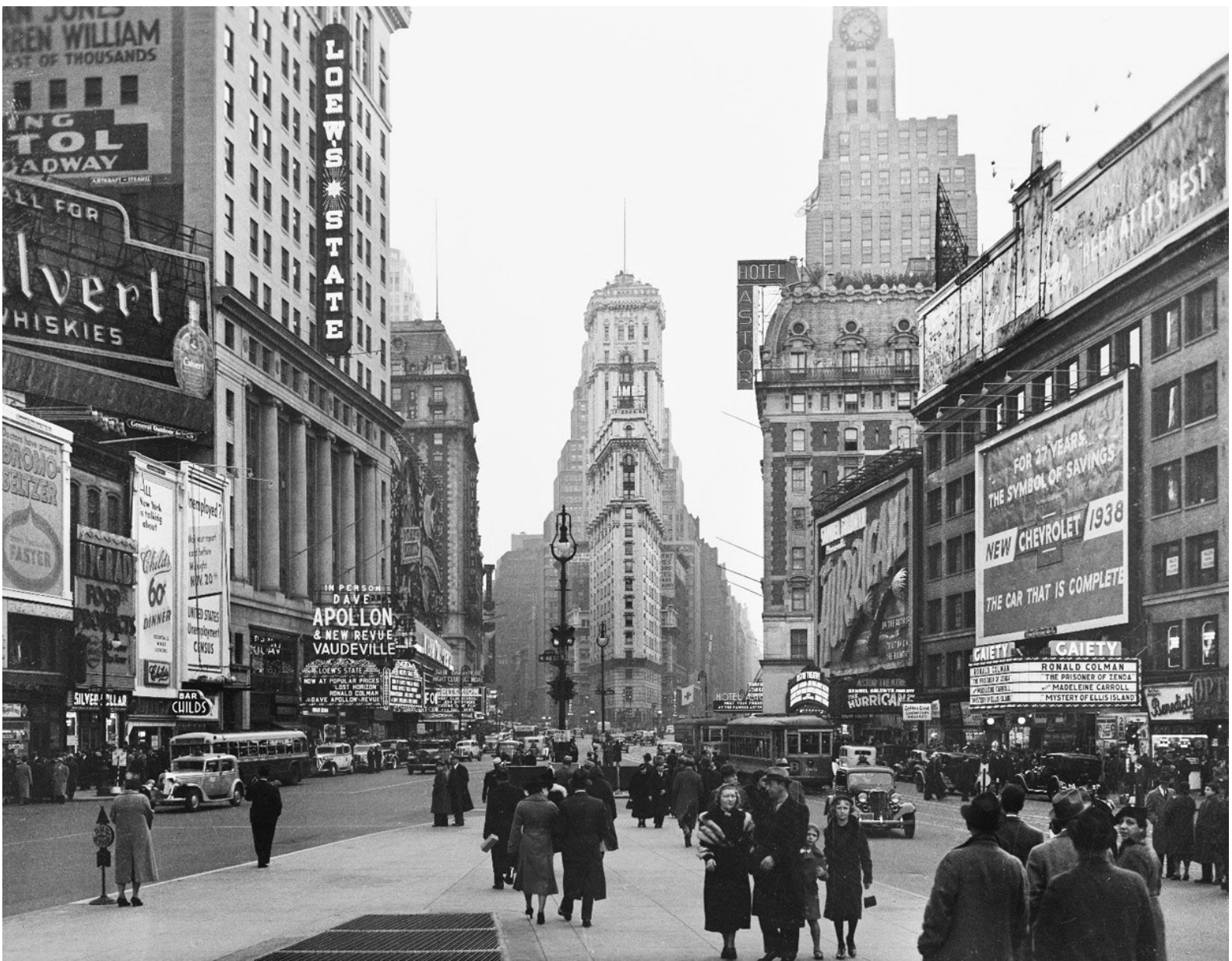

Fuente: Bofinger, E.M. / NYC Municipal Archives. Fotografía de enero de 1938, que capta la icónica y espectacular ambientación iniciada con carteles luminosos en 1904, para inundarse años después de tubos de neón o, incluso, mecanismos exhaladores de humo, mostrando progresivo afán de interactividad, como parte de un imaginario colectivo también emblemático de Picadilly Circus en Londres o Shibuya Hachikō en Tokio.

Igualmente, entre las dos posibles clases de actividad artística urbana, espontánea u organizada, Le Corbusier optaba por fomentar la primera, entendiendo que la inspiración creadora solo puede emanar de la vida misma, debido al impulso interior del propio ser (AA.VV., 1950 y 2012). Según él, la posibilidad de expresión no debe reservarse a profesionales; no hay que limitarse a construir convencionales teatros sino un anhelado marco para que cada cual se exteriorice o manifieste, aprovechando la capacidad de polivalencia que albergan los espacios, sirviéndose de cualquier elemento arquitectónico susceptible de cobijar sorpresas - planos inclinados, paredes ciegas... o cubos vacíos, como su boîte à miracles, una cajita mágica donde los sueños se pueden hacer realidad-, propiciando el espíritu popular de la vieja Comme- dia dell'Arte, donde todos podemos convertirnos en actores improvisados. En estos casos, la creación perecedera, transitoria, se impone a la permanente, en la medida que una atmósfera cambiante se adecua mejor al estado de ánimo, también variable a cada momento, dando respuesta a los sentimientos que se van sucediendo por medio de dinámicas formas, colores y sonidos, revelando el arte de manera explosiva o eruptiva, es decir, tomando «el corazón como lugar de expresión de la vida ${ }^{2}$.

Los planteamientos descritos se ejemplificaban con un amplio número de proyectos redactados por los propios asambleístas del CIAM en fechas previas. Entre los más destacados figuraban el anteriormente referido modelo para Saint-Dié así como el plan para 
Chandigarh (1951) de Le Corbusier, también suscrito por Pierre Jeanneret, Maxwell Fry y Jane Drew; y las ordenaciones para Chimbote (1946), Medellín (1948) y Bogotá (1949) realizadas por Sert en colaboración con Wiener. Aún así, finalmente, los postulados de ambos tendrían solo una parcial acogida, suscitando las críticas tanto de los más extremados continuistas como revisionistas modernos, en tanto que unos seguían confiando en la vigencia y el cumplimiento estricto de la Carta de Atenas, y los otros, entre los que se incluían futuros miembros de un Team 10 ya incipiente, como Bakema y Aldo van Eyck, querían romper absolutamente con ella, no asumiendo el concepto de corazón urbano desde un enfoque todavía asociado a la ortodoxa categorización de las cuatro funciones (Domhardt, 2012).

En todo caso, se había abierto un debate que, años después, según Colin Rowe y Fred Koetter (1976), mostraría reservas acerca de los preceptos dogmáticos formulados en el período de entreguerras para la nueva ciudad, desvelando una «cierta rebaja de apuestas y, posiblemente, los inicios de un reconocimiento de que el ideal de una neutralidad o una igualdad hecha de uniformidad resultaba apenas alcanzable, ni siquiera deseable» (p. 62). Aún así, en la práctica, este renovado interés por generar polos y suscitar confluencias no se concretaba por falta de un equipamiento adecuado, lo que se percibe, según ambos críticos, en el plan para Saint-Dié, donde los elementos estándar del urbanismo racionalista, incluso modificados de acuerdo a las nuevas convicciones, pasan a insinuar centralismo y jerarquía, desde su condición de receptáculo, pero mediante edificios exentos -entendidos como objetos- que no llegan a definir el espacio urbano, ofreciendo más bien una «esquizofrenia incumplida, iuna especie de acrópolis que tratase de funcionar como una versión del ágora!» (p. 62). En el extremo opuesto, a través de un escenario de mayor compacidad, experimentaciones como la de Harlow iban a resultar mucho más aceptadas, en tanto que utilizan los aspectos individuales de las construcciones con bastante discreción, intentando primar los valores de conjunto, sirviéndose de un vacío a modo de vestíbulo urbano que reinterpreta la concepción renacentista (ver FIG. 4).

\section{POLARIDADES METROPOLITANAS CONTEMPORÁNEAS}

\section{Retorno a las estructuras orgánicas}

La conciencia de que el medio urbano requiere focos catalizadores para estimular su vigor y flujo es algo que se ha ido afianzando durante la segunda mitad del siglo pasado, con posicionamientos desplegados en los años sesenta como el de Jane Jacobs (1961, pp. 182-256), basado en que los centros de actividad, «donde confluyen los caminos de muchas personas de una forma concentrada, son lugares social y económicamente importantes. Algunas veces [...] para la vida de la ciudad en su conjunto, y otras para la vida de un distrito o barrio» (pp. 425-426), considerando que se crean por la combinación de cuatro condiciones indispensables: mezcla de usos primarios, trazado de manzanas pequeñas, mínima proporción de edificios antiguos y congregación de personas; o el de Aldo Rossi (1966, pp. 72 y 157), para quien el aspecto colectivo constituye el principio y fin de cualquier urbe hasta el extremo de hablar de l'âme de la cités, a la par que añade que "toda ciudad posee un centro» (p. 122), entendido como algo que trasciende lo meramente espacial, cuyas características y complejidad pueden ser variables, habitualmente aglutinando al sector terciario, pero siempre en el desempeño de un rol específico dentro de la vida urbana, lo que es compatible con un sistema de varios núcleos que propicie relaciones interzonales. En suma, como sostiene Henri Lefebvre (1970), «La centralidad constituye para nosotros lo esencial del fenómeno urbano» (p. 122), gracias a lo cual, «la ciudad construye, libera, aporta la esencia de las relaciones sociales» (p. 124).

Tanto Jacobs como Rossi estaban ampliamente influenciados por la doctrina de teóricos coetáneos como Kevin Lynch (1960, pp. 91-98 y 125-127), quien recurrió a la idea de "nodo" para destacar lo que percibía como puntos estratégicos, con posibilidad de acceso público, resultantes bien de concurrencia de sendas o bien de condensaciones características -vinculadas a un fundamento temático-, o debido a una simultaneidad de ambos motivos. A su entender, en cualquier caso, pueden estar constituidos por enclaves concretos 0 , desde una perspectiva amplia, por barrios enteros, y no exigen una morfología o rasgos físicos vigorosos, ni tan siquiera determinados, aunque lógicamente sea un hecho que ayuda a reforzar su impacto, haciéndolos más memorables; en el fondo, lo importante es que manifiesten su esencia de lugares que no puedan confundirse con ningunos otros. Los nodos son los elementos conceptuales de sujeción de la trama urbana y que, obrando por irradiación, pueden organizar grandes distritos a su alrededor, con opción de disponerlos en serie formando una estructura conectada. 
FIGURA 4

FREDERICK GIBBERD: CENTRO DE LA NEW TOWN DE HARLOW (1947)

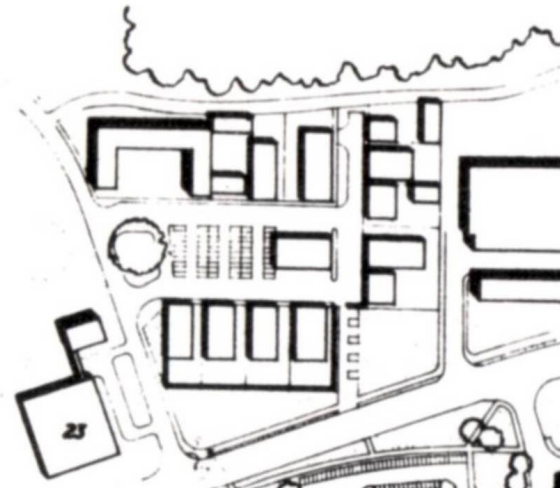

88

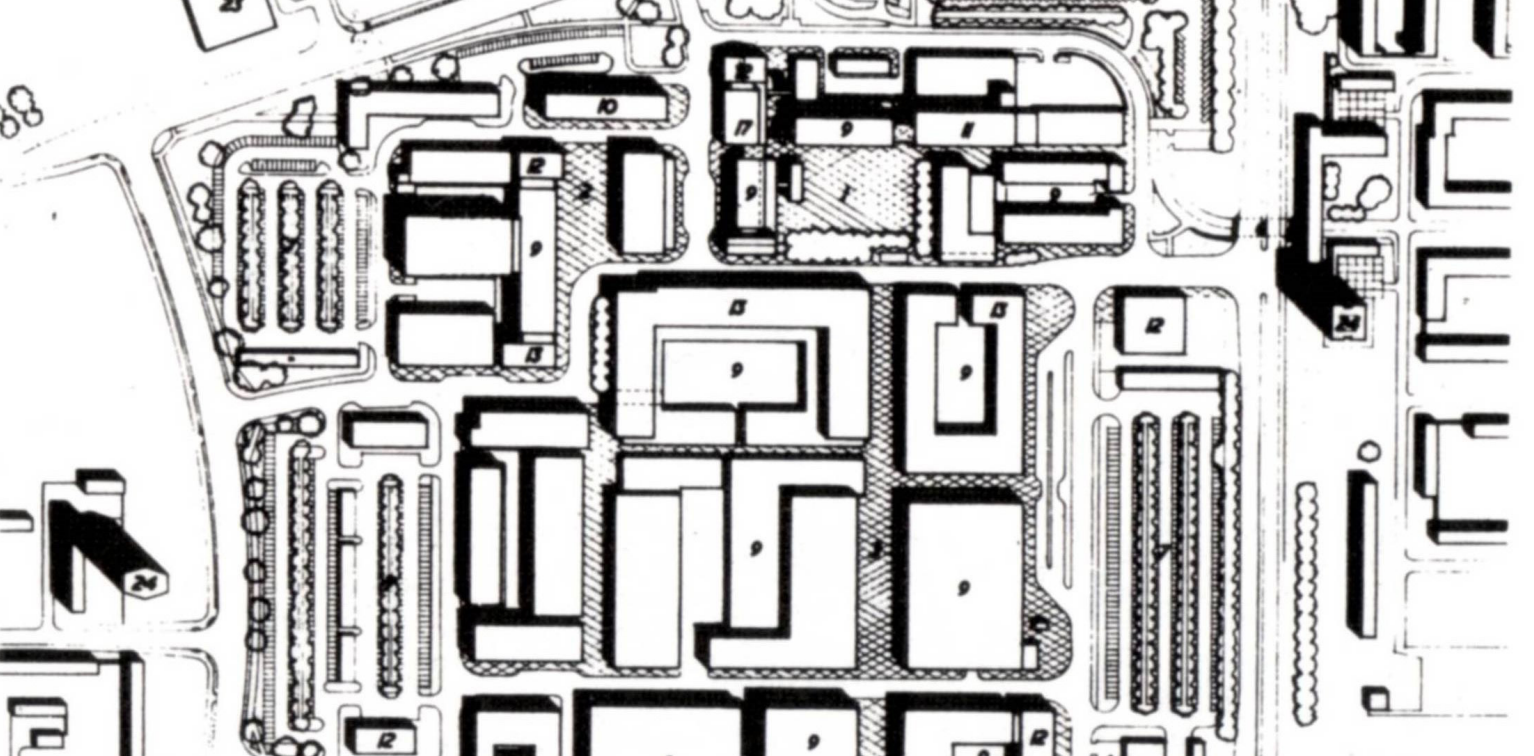

8
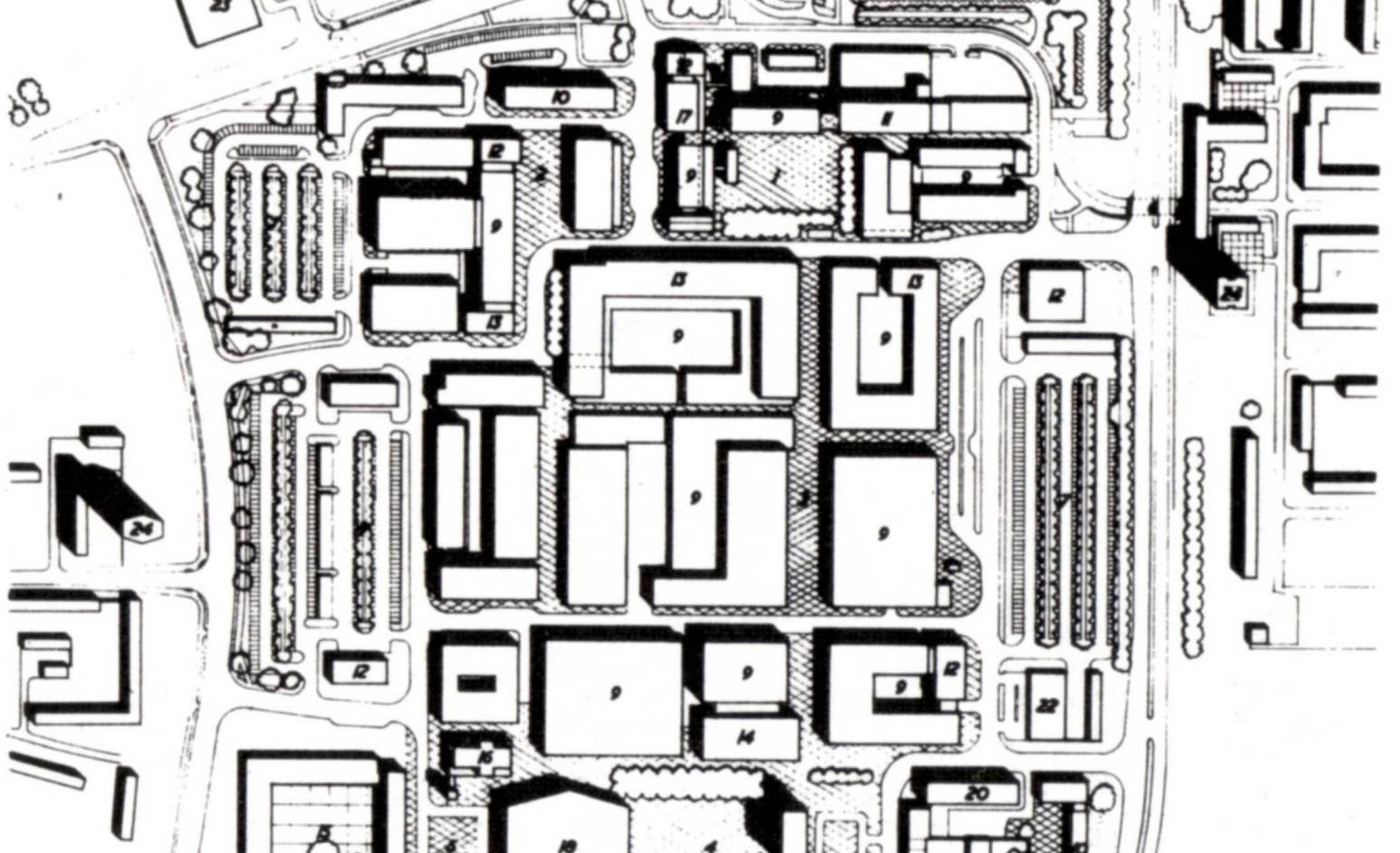

(n)m
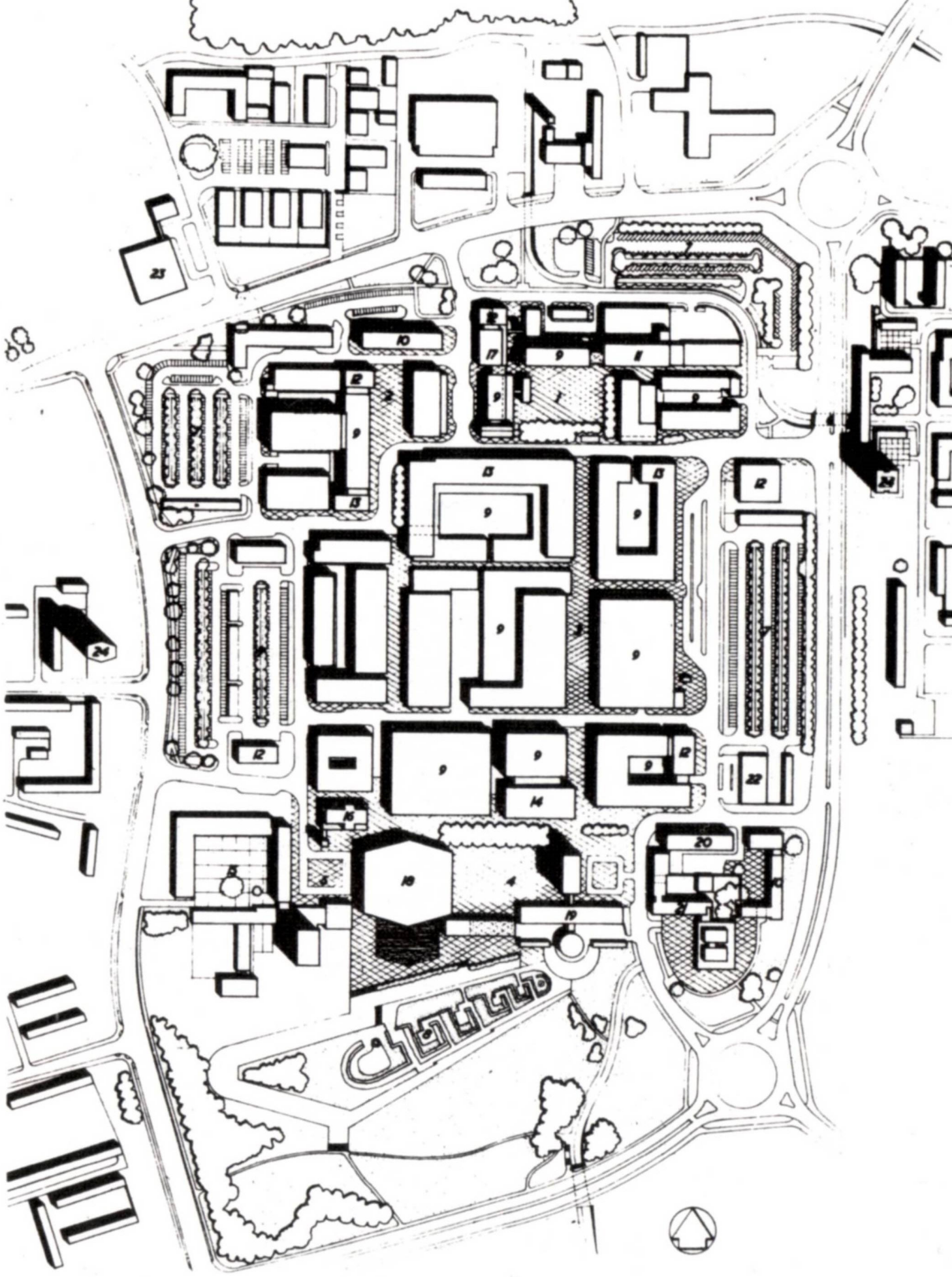
surge esta nueva ciudad a pocos kilómetros al norte, con previsión inicial de 60.000 habitantes, ideada totalmente autónoma en vez de como entidad satélite, cuyo punto neurálgico se inspira en las antiguas plazas italianas, incorporando bloques altos influenciados por la tipología de torre. 
Dichas encrucijadas muestran entidad propia a juicio, entre otros, de Christopher Alexander, Sara Ishikawa y Murray Silverstein (1977, pp. 76-79 y 164-167), a través especialmente de dos principios generales de diseño de su lenguaje combinatorio a nivel planificador. El primero, denominado como "la magia de la ciudad" (patrón 10), hace referencia a atractivos centros urbanos de comunidades de un tamaño aproximado de 300.000 habitantes; límite estimado para garantizar una proximidad de estos últimos respecto del núcleo que sea compatible con su encarecimiento inmobiliario, lo que induce a crear tantas cuencas de captación como áreas de tal magnitud haya en una región, dispuestas suficientemente repartidas -en una distancia variable que se llega a fijar entre 3,2 y 14,4 kilómetros en función de la densidad media poblacional- y con un grado de especialización conveniente. El segundo tipo, resultante de un crecimiento dirigido con forma de estreIla, consiste en "nudos de actividad" (patrón 30), necesarios para no mermar la capacidad de influencia de las instalaciones públicas por causa de una tenue diseminación, en tanto que estudios sobre conducta peatonal, como los realizados por Jan Gehl (1968 y 1971) o William H. Whyte (1980 y 1988), corroboran que la gente se busca a sí misma, llevada por su tendencia a la autocongestión, es decir, a su acumulación en torno a flujos o corrientes de tránsito; un hecho que insta, según Alexander, a la construcción de plazas bajo las siguientes cuatro premisas: ubicarse en la intersección de los ramales principales del viario; presentar un tamaño contenido; asignarles equipamientos y comercios de acuerdo a criterios cooperativos, atendiendo a vínculos simbióticos con los que sostenerse recíprocamente; y quedar distribuidas de manera uniforme, sin dejar casas o lugares de trabajo a más de trescientos metros. Todo ello sin perjuicio de poder complementarse con otros rasgos estructurales como el "núcleo excéntrico" (patrón 28) dentro de una comunidad; o la "calle comercial" (patrón 32) situada entre dos de estas.

Con relación a lo anterior, el propio Gehl (2010) completa la radiografía de los centros urbanos, recordándonos que, en la gran mayoría de ciudades, abarcan una superficie aproximada de un kilómetro cuadrado, lo que compagina con la distancia máxima que cualquier persona normal está dispuesta a caminar, que se cifra en unos quinientos metros; un objetivo real y razonable según refrenda el tamaño medio de las áreas centrales, apto para que los peatones puedan acceder a casi todos los servicios fundamentales que la ciudad ofrece (ver FIG. 5). Según el arquitecto danés, incluso metrópolis como "Londres o Nueva York tienen ciertos patrones a través de los cuales se dividen en centros y distritos menores» (p. 121), en sintonía con lo apuntado por su colega austriaco; en dichas capitales también es posible encontrar núcleos que cuentan con la extensión referida de recorrido pedestre. Un espacio que, en todo caso, debe permitir que haya un desarrollo de secuencias de acontecimientos significativas e inspiradoras, estimulándose mutuamente, con escenarios configurados con base en el limitado radio de acción de nuestros sentidos (Gehl, 1971, pp. 85 y 103).

Whyte (1988) abundaría al respecto, aunque alertando de una tendencia a la descentralización debida al advenimiento de la era digital; reconoce que todo centro debe poseer unos elementos básicos, consistentes en grandes aglomeraciones de peatones, concentración y mezcla de actividades, pero cuya reunión empieza a resultar algo incoherente en muchos casos -pese a estar bien definidos por sí mismos-, lo que hace que el conjunto se haya ido debilitando, en proporción directa a la expansión del back-office telemático, agravado por la falta de interconexiones entre polos. No obstante, estas ideas también hay que contextualizarlas en una progresiva deslocalización industrial, puesta en marcha a partir de la crisis del petróleo, germen de un nuevo modelo económico basado en el sector servicios, que iba a permitir transformar el paisaje urbano, reordenando sus funciones, principalmente, en favor de mayores áreas de consumo, tanto o más volubles a las recesiones de mercado (Berman, 1982, y García, 2008), lo que ha obligado, a su vez, a buscar nuevas estrategias de planificación, otros puntos de apoyo de carácter permanente, proyectando una imagen como espacio cultural y recreativo, donde el bienestar prima por encima de cualquier otra cuestión. Como afirma Ernesto N. Rogers, el corazón de la ciudad no puede ser la fábrica, símbolo de la sociedad proletaria, ni tampoco el centro comercial, como ocurre en las organizaciones capitalistas, sino que debe ser el centro de unas relaciones humanas mucho más ricas y gratificantes: «conversación, discusión, 'shopping', 'piropeo', 'flâner' y el inefable 'dolce far niente' en su más puro significado; la expresión natural de la contemplación y el ocio para la apacible satisfacción de cuerpo y espíritu» (Rogers et al., 1952, p. 73) ${ }^{4}$.

Así, no fueron pocos los proyectos posmodernos que se hicieron eco de estos planteamientos, asumidos especialmente por italianos y alemanes. No obstante, desde una apuesta arquitectónica más innova- 


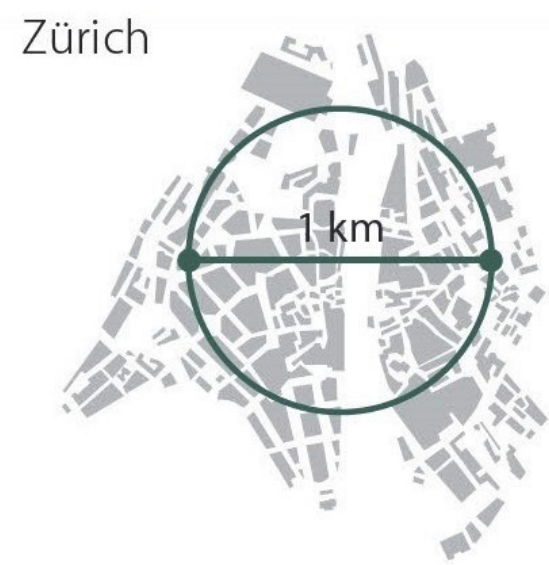

Pittsburgh

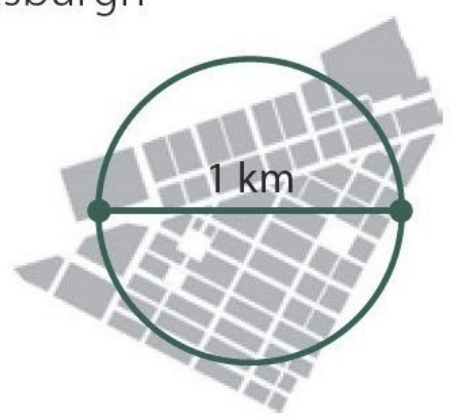

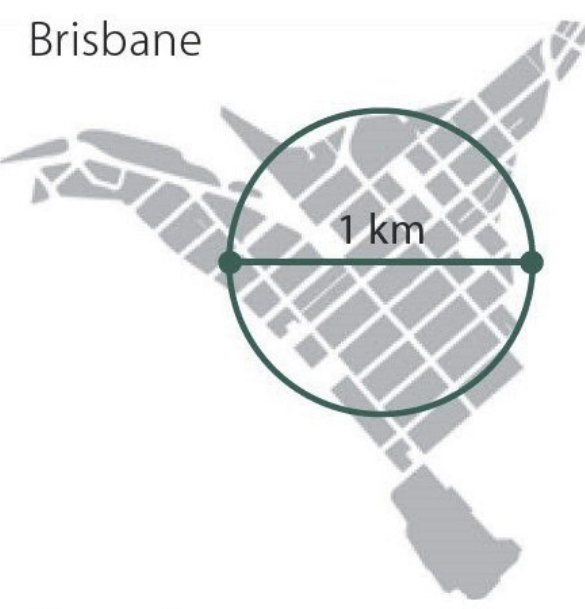

Copenhague

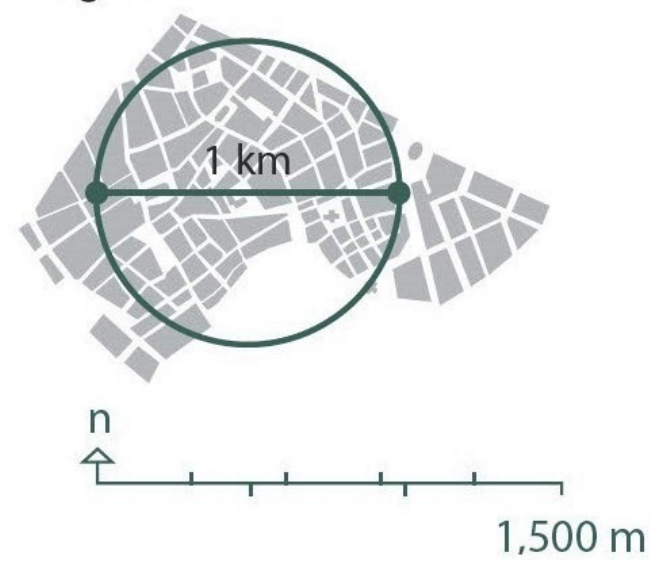

Fuente: Gehl, 2010, p. 121. En esta misma publicación, promovida por ONU-Hábitat, se hace referencia a que las personas andan a una velocidad media de $5 \mathrm{~km} / \mathrm{h}$, lo que implica que el tiempo empleado en atravesar los centros urbanos estudiados no sobrepasa los quince minutos -coincidente con el 1/4 d'heure de marche à pieds calculado por Le Corbusier para cruzar su ya mencionado centro cívico de Saint-Dié.

dora, Richard Rogers - primo del ya citado componente del grupo BBPR- junto a Renzo Piano serían los que llevaran a cabo uno de los referentes contemporáneos más ilustrativos de lo expuesto: el proyecto del Centre Pompidou de París (1971-1977), donde la importancia del sentimiento ciudadano es sinónimo de vivacidad y humanidad ${ }^{5}$. Como su autor inglés comenta, cuando las autoridades aceptaron su propuesta de liberar la mitad del solar asignado a la obra con objeto de dedicarlo a una plaza, estaban fomentando la relación con el entorno, su vuelco hacia el exterior -a lo que también contribuye la gran transparencia de su envolvente-, para regenerar los barrios de Beauborg y Le Marais como así ha ocurrido de manera ejemplar (Rogers y Gumuchdjian, 1997, pp. 15-16); esta idea procedía de su admiración por espacios públicos tales como la plaza Jemaa el-Fna en Marrakech, la plaza del Campo en Siena y la plaza de San Marcos en Venecia, a la que Le Corbusier puso el calificativo de bestiaire fraternel (Dardi, 2009, p. 184). García Vázquez (2008, pp. 8283) apunta que se trata de uno de los pocos edificios de carácter simbólico que ha respetado la denominada por él como "ciudad del espectáculo", sobreviviendo como hito dentro del actual panorama artificial y superficial -a su entender, "disneylandizado"- que la explotación lucrativa de la metrópolis origina en su, cuando menos, extravagante cóctel de ocio, cultura y consumo (ver FIG. 6). 


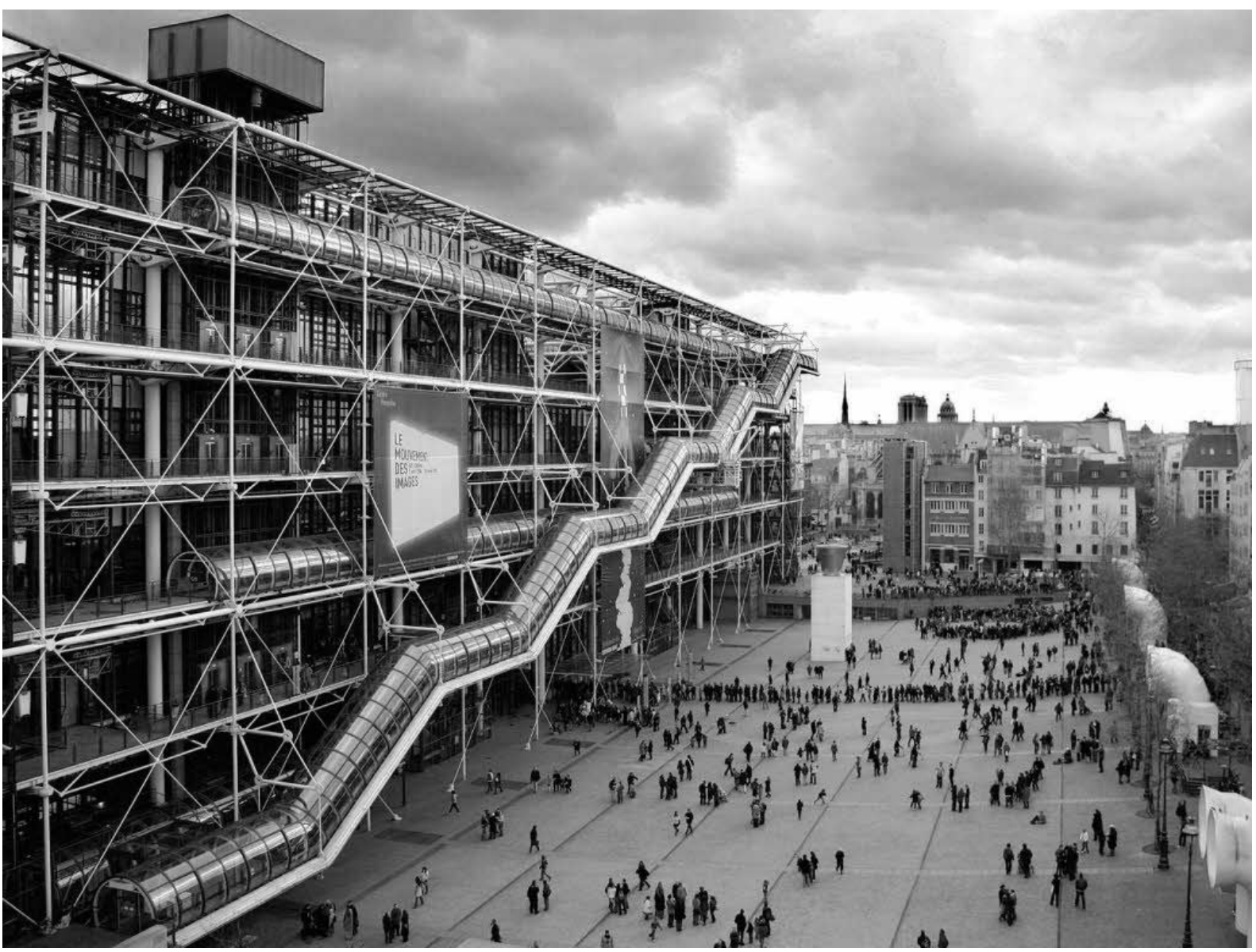

Fuente: Loic Venance / AFP Archives. La esencia del proyecto, gracias a la compactación de sus cien mil metros cuadrados, responde a un reparto de dos hectáreas de terreno entre edificio institucional y plateau exterior a modo de patio de entrada -con suave descenso hacia el vestíbulo-, donde deambular y contactar sin que nada esté programado, catalizando una sinergia de usos.

\section{Nuevos paradigmas}

Más recientemente, movido por otros desarrollos también incontrolados, el propio Richard Rogers propone una fórmula de sostenibilidad basada en la reinterpretación de la "ciudad densa», criticando el ejemplo de corte simplista norteamericano, donde se zonifican las funciones con un eje de oficinas rodeado de zonas residenciales enlazadas por autopistas que se remata con un tercer cordón de áreas comerciales y de ocio en las afueras. En su puesto, la también llamada "ciudad compacta» se aglutina "alrededor de centros de actividad social y comercial, conectados por transporte público, constituyéndose en focos en torno a los cuales crecen los barrios», recuperando «la ciudad como hábitat ideal de una sociedad basada en la comunidad [...] que puede fácilmente responder a la variedad cultural» (Rogers y Gumuchdjian, 1997, pp. 38 y 40). Las industrias contaminantes están ya casi extinguidas en el primer mundo, por lo que no parece que haya riesgo sanitario para condensar y solapar nuestros quehaceres, pudiendo reconsiderarse las ventajas sociales de la cercanía y de vivir acompañados: las comunidades participan y arraigan en sus respectivos vecindarios a la par que se reduce el consumo de recursos y se dispone de mayor movilidad con menor polución.

A este propósito, en concatenación con las teorías de los años sesenta, destaca la reciente proliferación en otras latitudes, incluso del continente asiático, de actuaciones que tienden a la superposición de redes artificiales -infraestructuras de toda clase-, con una disposición similar al esquema neuronal (Montaner, 
2008, pp. 201-202); y, obviamente, referirse a ellas significa hablar de nudos o, si se prefiere, de nodos. Así, según el catalán, se genera una malla sin centro ni periferia; aunque, visto desde otra óptica ¿no podría decirse que con muchos pequeños centros que absorben una parte alícuota de protagonismo del gran núcleo original?; o, llevado al extremo ¿no equivaldría integralmente a «una esfera infinita cuyo centro está en todas partes y la circunferencia en ninguna» ${ }^{6}$ ? En cualquier caso, se materializa en un sistema discretizado o pixelado de puntos, conectados de numerosas maneras, que suelen ser intercambiadores de transporte junto a grandes superficies de esparcimiento, aflorando de la tierra como un géiser que estalla por razón de su energía, a los que Manuel de Solá-Morales (2004) llamó «esquinas territoriales» (ver FIG. 7). Al hilo de lo anterior, desde una actitud de rechazo al urbanismo racionalista, Lefebvre (1968) expone: «por lo que respecta a países industriales, es lícito concebir ciudades policéntricas, centralidades diferenciadas y renovadas e incluso centralidades móviles (culturales, por ejemplo)» (p. 90), lo que relativiza el valor de la posición o situación geométrica de un lugar.

El ejemplo oriental también es citado, en oposición a los tipos tradicionales, por Rem Koolhaas (1997), quien nos revela su inclinación por el modelo de «ciudad genérica», muy experimentado últimamente, cuya característica principal es que está «liberada de la cautividad del centro, del corsé de la identidad» (p. 12). A su parecer, una alternativa muy deseable pues emancipa a la periferia -cada vez más grande en las metrópolis- de su colapsado núcleo, que suele rendir excesivo culto a un legado histórico insistentemente resonante, lo que Lefebvre (1968) no ve cosa fácil puesto que «La desaparición de la centralidad no se impone ni teórica ni prácticamente» (p. 90). En este caso, la vertebración se logra no por cuenta de un ámbito público demasiado exigente -progresivamente degradado en una larga secuencia en la que el foro romano es al ágora griega lo mismo que el centro comercial es a la calle mayor-, sino gracias a lo 'residual', lo que para la modernidad consistía simplemente en una zona verde. Se consigue así un ambiente urbano sereno, cuya composición con predominio de la verticalidad- adopta un estilo libre, con sus tres ingredientes básicos (carreteras, edificios y naturaleza) coexistiendo con relaciones flexibles, sin buscar una evolución normal que estratifique la urbe con el paso del tiempo sino, más bien, un formato de 'usar y tirar', cuyo destino final sea su abandono para ser sustituida por otro emplazamiento; paradójicamente, sólida en su construcción pero efímera en su condición, no reciclable sino desechable.
En definitiva, se puede observar una heterogeneidad de criterios, alentadores de ciudades con distinto esquema organizativo. $\mathrm{Y}$ es que, según Ernesto $\mathrm{N}$. Rogers, el problema de cuántos centros debe tener una ciudad constituye una cuestión meramente técnica; él piensa que lo importante es que cada uno de ellos sintetice todas las principales actividades posibles, pues los que son especializados resultan humanamente incompletos: «el corazón es el centro integral para una sociedad» (Rogers et al., 1952, p. 73). Un pronunciamiento en línea con Whyte (1988), quien denomina "lugares $100 \%$ » a aquellos espacios donde cabe encontrar una mezcla equilibrada de cualidades y calidades urbanas, de tal modo que satisfacen completamente nuestros requerimientos funcionales -pasear, descansar, conversar, escuchar...-, gracias a un conjunto arquitectónico idóneo tanto en su concepción global -tamaño, proporciones, materiales, colores, etc.- como en el más mínimo detalle, constituyendo sitios «donde la gente quiere estar». Fenómeno que permite que, Lefebvre (1970, pp. 122126), entre otros, también resalte su forma abstracta original -aunque luego se concrete en la práctica-, en la medida que subordina el contenedor a su contenido (cosas, objetos, individuos y situaciones), lo que le impide adoptar un sistema único, generalizado, como norma; de ahí su tendencia, indistintamente, tanto a la centralidad como a la policentralidad u omni-centralidad, ya sea hacia la construcción de determinados centros -aunque análogos, eventualmente complementarios- o hacia una sustancial dispersión y segregación. Como recalca el intelectual francés, «El hecho de que cualquier punto pueda ser tomado como centro, es lo que caracteriza al espaciotiempo urbano» (p. 122).

\section{CONCLUSIONES}

De todo lo anterior cabe deducir que, desde finales del siglo XIX, los centros urbanos han ido ejerciendo un papel cambiante en el conjunto de la ciudad, que viene ligado a su diferente consideración y tratamiento en cada época. Las transformaciones industriales supusieron una ruptura con los modelos tradicionales, que devinieron en otros de fuerte componente reformista, coincidentes en el tiempo con novedosas propuestas que, según los casos, mostraban un carácter utópico, descontextualizado, especulativo... incapaces de dar respuesta a muchos de los problemas y demandas sociales que se suscitaban. Los nuevos desarrollos consumaron la disolución de los núcleos centrales, ensombrecidos por una periferia masificada de suburbios carentes de vida comunitaria. Una co- 
FIGURA 7

HELMUT JAHN: SONY CENTER EN POTSDAMER PLATZ, BERLÍN (1993-2000)

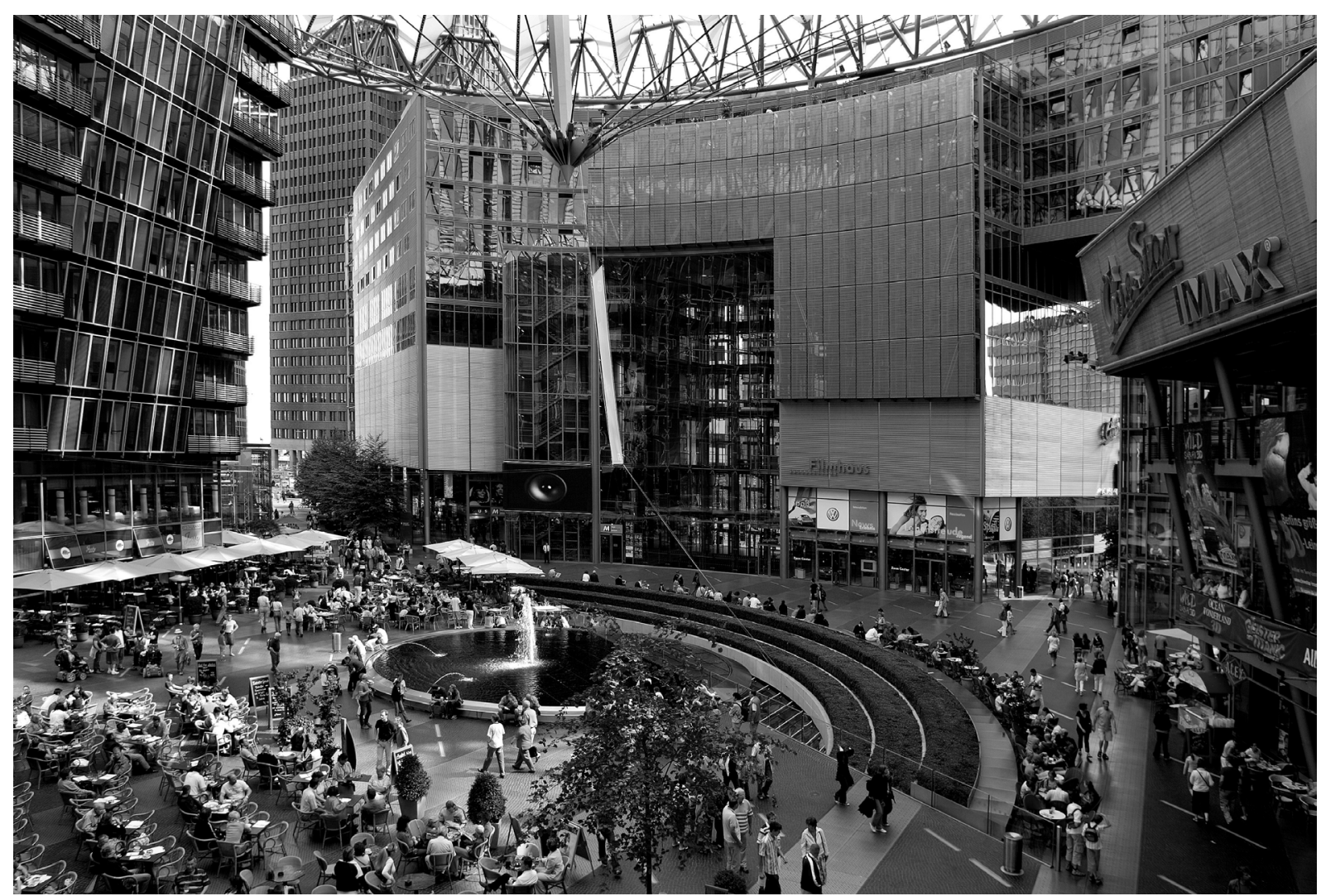

Fuente: Wolfgang Scholvien (http://flic.kr/p/7WvgPQ). El complejo, cabecera del Kulturforum, se vertebra alrededor de un gran atrio elíptico rematado por una cubierta radial, albergando oficinas, comercios, restaurantes, cafés, hotel y cines -que acogen eventos como el Internationalen Filmfestspiele Berlin (Berlinale)-, aparte de viviendas, junto a una estación de metro.

yuntura que no fue inicialmente atendida por la arquitectura moderna, que solo hizo alusiones puntuales al fomento de la convivencia en el marco de los CIAM celebrados durante los años treinta. Tras el motivo de inflexión que supuso el manifiesto de los „Nueve puntos", se allanó el terreno para que el octavo congreso, en un clima de regeneración posbélica, se dedicara a cuestionar los principios del urbanismo racionalista respecto al "corazón de la ciudad", el cual se recuperaría como premisa fundamental en la planificación, ya fuera con enfoques continuistas o rupturistas. En

\section{NOTAS}

1. Resulta significativo el hecho de que el congreso se hiciera coincidir en fechas con el Festival of Britain, celebrado en Londres; un destacado evento que, pese a no alcanzar la consideración de Exposición Internacional, constituía un cercano episodio de regeneración urbana en una zona relativamente cualquier caso, volvían a conjugarse los conceptos de centralismo y jerarquía, definitorios de una estructura orgánica, en una versión actualizada que, más tarde, ha sido sometida nuevamente a revisión desde posicionamientos contemporáneos, en los que se pone el énfasis en lograr sistemas integrados, de máxima cohesión, a partir de la creación de suficientes elementos dinamizadores de conjunto, especialmente de uso cultural y lúdico, edificados o en forma de espacios abiertos, pero siempre con el decidido objetivo de promover experiencias compartidas.

céntrica -germen del importante foco cultural en que, actualmente, se ha convertido la South Bank.

2. Expresión con la que Le Corbusier quiso titular su artículo escrito con motivo del octavo CIAM, en vez del que sería definitivo ("El corazón como punto de 
encuentro de las artes"), según él mismo refleja en Rogers et al., 1952, p. 41; y de la que también trata el texto de Bakema de la misma publicación, pp. 67-68.

3. La expresión francesa, cuya traducción es "el alma de la ciudad", se toma prestada del geógrafo Paul Vidal de la Blache.

4. Una circunstancia que se percibe perfectamente en las capitales que, agudizando la imaginación de sus gentes, han tratado de reinventarse, pro-

\section{BibLIOGRAFÍA}

AA.VV. (1950). Architecture et Dramaturgie. París, Francia: Flammarion -incluye el texto "Le théâtre spontané" de Le Corbusier-.

AA.VV. (2012). Massilia 2012 (Annuaire d'études corbuséennes): La boîte à miracles. Le Corbusier et le théatre. Marsella, Francia: Fondation Le Corbusier y Éditions Imbernon.

Alexander, C., Ishikawa, S., y Silverstein, M. (1977 [1980]). Lenguaje de patrones. Barcelona, España: Gustavo Gili,.

Baudrillard, J. (1978). L'effet Beauborg. París, Francia: Galilée.

Benevolo, L., Melograni, C., y Giura Longo, T. (1977 [2000]). La proyectación de la ciudad moderna. Barcelona, España: Gustavo Gili,.

Berman, M. (1982). All that is solid melts into air. The experience of modernity. Nueva York, EE.UU.: Simon \& Schuster.

Borges, J. L. (1952). Otras inquisiciones. Buenos Aires, Argentina: Sur.

Burckhardt, J. (1898). Griechische kulturgeschichte. Berlín y Stuttgart, Alemania: Spemann.

Ciucci, G., Dal Co, F., Manieri-Elia, M., y Tafuri, M. (1975). La ciudad americana, de la guerra civil al New Deal. Barcelona, España: Gustavo Gili.

Dardi, C. (2009). Architetture in forma di parole. Macerata, Italia: Quodlibet (incluye, entre otros textos: Place d'Italia (pp. 173-190), escrito en 1988 a propósito del proyecto Agorà: le piazze storiche dell'Italia meridionale e insulare).

Domhardt, K. S. (2012). The heart of the city. Die stadt in den transatlantischen debatten der CIAM 19331951. Zúrich, Suiza: GTA-ETH. gramando la celebración de competitivos eventos para satisfacción propia y atracción de visitantes (festivales, exposiciones, acontecimientos deportivos, etc.).

5. Acerca de su carácter mediático, véase Baudrillard, 1978, que no elude una severa crítica a su faceta lucrativa como 'hipermercado del arte'.

6. Véase el análisis histórico, en clave metafórica, de este concepto en Borges, 1952, pp. 5-7.

García Vázquez, C. (2008). Ciudad hojaldre. Visiones urbanas del siglo XXI. Barcelona, España: Gustavo Gili.

Gehl, J. (1968). Mennesker til fods. Arkitekten, 20, 429-46.

Gehl, J. (1971 [2009]). La humanización del espacio urbano: la vida social entre los edificios. Barcelona, España: Reverté.

Gehl, J. (2010 [2014]). Ciudades para la gente. Buenos Aires, Argentina: Infinito.

Giedion, S. (1941 [2009]). Espacio, tiempo y arquitectura. Barcelona, España: Reverté.

Giedion, S. (1957 [1963]). Arquitectura y comunidad. Buenos Aires, Argentina: Nueva Visión.

Giedion, S. (1997). Escritos escogidos. Murcia, España: COAATM, Librería Yebra y Cajamurcia.

Hastings, H. de C., Tatton Brown, A., y Tatton Brown, W. E. (1937). Communication du Groupe Anglais. En Le Corbusier (Ed.), Logis et loisirs: 5e congrès CIAM, Paris, 1937 (pp. 79-80). Boulogne-sur-Seine, Francia: L'Architecture d'Aujourd'hui.

Jacobs, A. B. (1993 [1996]). Grandes calles. Santander, España: Universidad de Cantabria.

Jacobs, J. (1961 [2013]). Muerte y vida de las grandes ciudades. Madrid, España: Capitán Swing.

Koolhaas, R. (1997 [2007]). La Ciudad Genérica. Barcelona, España: Gustavo Gili.

Kostof, S. (1992). The assambled city. Londres, Reino Unido: Thames \& Hudson.

Le Corbusier (1943 [1971]). Principios del Urbanismo (La Carta de Atenas). Barcelona, España: Ariel.

Lefebvre, H. (1968 [1978]). El derecho a la ciudad. Barcelona, España: Península. 
Lefebvre, H. (1970). La revolución urbana. Madrid, España: Alianza.

Lynch, K. (1960 [2006]). La imagen de la ciudad. Barcelona, España: Gustavo Gili.

Montaner, J. M. (2008). Sistemas arquitectónicos contemporáneos. Barcelona, España: Gustavo Gili.

Ortega y Gasset, J. (1930 [1956]). La rebelión de las masas. Madrid, España: Espasa Calpe.

Palladio, A. (1570 [1988]). Los cuatro libros de la arquitectura. Madrid, España: Akal.

Pausanias (s. II d. C. [1994]). Descripción de Grecia. Libros VII-X. Madrid, España: Gredos.

Rogers, E. N., Sert, J. L., y Tyrwhitt, J. (Ed.) (1952 [1955]). El corazón de la ciudad: por una vida más humana de la comunidad. Barcelona, España: Hoepli.

Rogers, R., y Gumuchdjian, P. (1997 [2000]). Ciudades para un pequeño planeta. Barcelona, España: Gustavo Gili.

Rossi, A. (1966 [1986]). La arquitectura de la ciudad. Barcelona, España: Gustavo Gili.

Rowe, C., y Koetter, F. (1976 [1981]). Ciudad Collage. Barcelona, España: Gustavo Gili.
Sica, P. (1977 [1981]). Historia del urbanismo: el siglo $X I X$, vol. 2… Madrid, España: Instituto de Estudios de Administración Local.

Sitte, C. (1889). Construcción de ciudades según principios artísticos. En G. R. Collins, C. C. Collins y C. Sitte (1980), Camillo Sitte y el nacimiento del urbanismo moderno. Construcción de ciudades según principios artísticos (pp. 149-428). Barcelona, España: Gustavo Gili.

Solá-Morales, I. de (1992). Werner Hegemann y el arte cívico. En W. Hegemann y E. Peets (1922). El Vitruvio americano: manual de Arte Civil para el arquitecto (s.p.). Barcelona, España: Fundación Caja de Arquitectos -como prólogo de la edición en castellano.

Solá-Morales, M. de (Ed.) (2004). Ciutats, cantonades /Villes, carrefours, catálogo de exposición. Barcelona, España: Lunwerg.

Unwin, R. (1909 [1984]). La práctica del urbanismo. Una introducción al arte de proyectar ciudades y barrios. Barcelona, España: Gustavo Gili.

Whyte, W. H. (1980). The social life of small urban spaces. Washington D.C., EE.UU.: The Conservation Foundation.

Whyte, W. H. (1988). City: rediscovering the center. Nueva York, EE.UU.: Doubleday. 